\title{
Empathy from the perspective of oncology nurses
}

\author{
Maryam Sedaghati Kesbakhi ${ }^{1,2}$, Camelia Rohani ${ }^{{ }^{*}}$, Jamileh Mohtashami ${ }^{1}$ and Malihe Nasiri ${ }^{1}$
}

\begin{abstract}
Background: Empathy is the ability to put yourself in the place of others and understand their feelings and experiences. Empathy with cancer patients is essential in all disease stages. The purpose of our study was to determine the level and type of empathy in a sample of Iranian oncology nurses and to investigate the relationship between nurses' empathy and their demographic characteristics.

Methods: This is a descriptive study with cross-sectional design, which was carried out by a convenience sample of oncology nurses $(n=181)$. They answered the Jefferson Scale of Empathy-Nursing Student version R (JSE-NS version R), and the Interpersonal Reactivity Index (IRI). Independent t-test and ANOVA were used to determine the difference of empathy based on various demographic variables. The relationship between empathy and significant demographic variables were evaluated by multiple linear regression (MLR) analyses.

Results: The mean age of the oncology nurses was $34.9 \pm 6.7$ years. The mean score of empathy was $106 \pm 16.5$ (range of 20-140) using the JSE-NS version R. Based on the IRI subscales, the mean score of empathic concern (20.5 \pm 5.8 ) was higher in comparison with the subscales of perspective-taking (14.6 \pm 3.5$)$, fantasy $(11.0 \pm 5.5)$, and personal distress (14.0 \pm 4.5$)$. MLR models showed that the variables of age $(\beta=0.22, p \leq 0.005)$, marital status $(\beta=0$. $21, p \leq 0.006)$, and having children, $(\beta=0.19, p \leq 0.012)$ predicted $22 \%$ of changes in the nurses' empathy, respectively.

Discussion: This study showed that empathy is more emotional than cognitive in this sample of oncology nurses. As a cognitive response is more dependent on subjective judgments, there is a possibility to increase the level of this kind of empathy.
\end{abstract}

Conclusions: Empowering oncology nurses is necessary in the field of cognitive empathy, by periodic measurements, and in-service training programs with focus on nurses' experiences.

Keywords: Empathy, Patient, Oncology nursing

\section{Background}

Cancer is a reason for disability and premature death, accounting for a large share of the worldwide health care system services [1]. In Iran, cancer is the third leading cause of death after cardiovascular diseases and accidents [2]. According to statistics of the Ministry of Health and Medical Education, annually more than 30,000 cancer deaths and 70,000 new cases occur in Iran [3]. Cancer patients are confronted with fears associated with unclear situations following the disease and treatments, in addition to physical and mental dysfunctions [4]. Thus, communication of

\footnotetext{
* Correspondence: camelia.rohani@sbmu.ac.ir

${ }^{1}$ Department of Nursing, School of Nursing \& Midwifery of Shahid Beheshti

University of Medical Sciences, Tehran, Iran

Full list of author information is available at the end of the article
}

nurses with patients is an important element of the caring process [5]. One of the main roles of nurses is, understanding the patients, their needs, feelings, and situations, and empathy is the basis of this understanding [6]. Oncology nurses have a chance to develop their empathy with cancer patients, and to support them and their families during the period of hospitalization [7]. They have an essential role in the psychosocial support of the patients [8]. This means having a good communication with the patient, developing empathy with him/her, and providing psychosocial and spiritual care based on culture [9].

A literature review show that the theory of empathy has a very long and rich history, going back to the late nineteenth Century. The word of empathy was derived from the German word of Einfuhlung, which is translated from the 
Greek word of Empatheia (understanding factors beyond themselves) [10]. Basic definitions of empathy are related to the internalization of emotions of others, determined by observing or self-projection [11]. Empathy stands for understanding the feelings and concerns of others according to their worldview [11]. It means experiencing emotions of another person that are congruent with [12], and different from compassion. Compassion is the ability to feel for another human-being and aim to relieve its suffering [13]. Empathy is more cognition than emotion. On the contrary, sympathy is in more emotion. Compassion, settles in the region of overlap between empathy and sympathy [14]. Vreeke and van der Mark [15] stated that perhaps genuine empathy involves the experience of compassion and caring.

Empathy in nursing is defined as a human, professional, and caring trait in the process of communication with patients [16]. Carl Rogers described the concept of empathy in his articles, according to whom; empathy is the process of having the same feelings like others and having an emotional connection with them [17], or feeling the world of the patient in a way that this feeling is your own feeling [10]. He discussed subjective and objective empathy, and believed that subjective empathy is paying attention to your own personal reactions in response to the patient's experience, and objective empathy is using external information, such as theories or concepts as a way to better understand the patient's experiences [18].

Empathy is a basic capacity in individuals for adjusting communications and for supporting common activities. This ability has a fundamental role in human's social life [19]. It is considered as an essential component for successful interpersonal skills [20]. Empathy has a multidimensional construct, including emotional, cognitive, moral, and behavioral dimensions [21]. Early investigators had a tendency to discriminate between cognitive and emotional dimensions, even though in recent years they were leaning towards a more integrated approach $[22,23]$. Cognitive empathy is an ability to identify and understand the patients experience; emotional empathy means the ability to experience and identify emotions; moral empathy is an inner incentive to empathize; and behavioral empathy is the ability to transfer the understanding of empathy to the patient [24]. Empathy is the center of subtle understanding, judgment, and ethical performance of humans [25]. Some researchers discussed "clinical empathy", as a compassionate professionalism, and introduced it as a skill to stand in the patient's shoes and to get across an understanding of the patient's situation as well as the tendency to help [26, 27]. The American Association of Medical Colleges (AAMC) has recorded "clinical empathy" as one of 13 sub-competencies of clinical communication that should be assessed and taught in medical schools [28].
Studies show that empathy is affected by various situational and personality factors, such as genetics, gender, education and culture [19]. Davis et al. [29] evaluated empathy in more than 800 pairs of monozygotic and dizygotic twins and found that empathic concern and personal distress are partially derived from genetic factors. They estimated that $28 \%$ and $32 \%$ of differences in empathic concern and personal distress are respectively related to genetics.

Empathy and having a good communication with the patient, and assessment skills for understanding of the patient are essential and contribute to nurses developing a good clinical communication with the patient and their families. Nurses try to prepare individual care for every patient and to establish an empathic communication with him/her, because each patient requires physical and psychosocial care in accordance with his/her symptoms and special needs [7]. The level and type of empathy of nurses are important also, affecting the hope of patients and their families [30]. Lack of empathy and poor patient care may lead to patient displeasure and even legal complaints from the nurse due to negligence in patient care [31]. Empathic interactions lead to understanding of experiences, concerns and perspectives of the patient, and consequently positive outcomes, such as patient satisfaction and more compliance in patients [11]. In addition, empathy increases patient care management, reduces financial needs of the health care system, treatment course, and need for sources [32]. With respect to the special place of empathy in the nurse-patient relationship, especially in oncology wards, the researchers carried out a study on empathy perspectives in a sample of Iranian oncology nurses.

\section{Methods}

\section{Aims}

The objective of this study was to determine the level and type of empathy in a sample of Iranian oncology nurses in educational hospitals affiliated with Universities of Medical Sciences in Tehran as well as to investigate relationship between nurses' empathy and their demographic characteristics.

\section{Design}

This is a descriptive study with cross-sectional design, which was carried out in a sample of oncology nurses.

\section{Participants and setting}

In this study, 181 nurses working in oncology, hematology and stem cell transplantation adult wards were recruited by convenience sampling from seven hospitals affiliated to three Medical Universities in Tehran. According to previous similar studies $[33,34]$ and the sampling formula (95\% confidence level, relative estimate 
error level of one) optimum sample size was calculated to be 164 individuals. Because of attrition risk, the sample size was increased by $25 \%$ to 205 individuals. Inclusion criteria in this study was working as a full-time nurse with a bachelor's degree or higher in nursing, and having at least 6 months experience in the field of oncology. Since, there is still no certificate for oncology nursing in Iran.

\section{Instruments}

Data related to the level and types of empathy were collected with a specific, and a general tool. A demographic information questionnaire was also used to collect personal information and medical history.

\section{Jefferson Scale of Empathy-Nursing Student version $R$ (JSE-NS version $R$ )}

The Jefferson Scale of Empathy (JSE) has multiple versions [35-37]. It was constructed on the basis of an extensive review of literature, followed by pilot studies with different groups of medical students, residents and physicians [38]. This scale was translated to 53 languages and was applied in more than 83 countries [39]. In this study, the Persian version of the JSE-Nursing Student version $\mathrm{R}$ (JSE-NS version $\mathrm{R}$ ) as a specific tool for measurement of empathy with 20 items was used [40]. The original version of the scale contains three factors (perspective taking, compassionate care, and standing in patient's shoes) [35], but in an initial study on the Persian version of the scale, it showed a four-factor structure [40]. The respondents need to quantify the level of their agreement with each of the items from strongly disagree ( 1 score) to strongly agree $(7$ score) on a seven-point Likert-type Scale. To calculate the scoring tool, items number $1,3,6,7,8,11,12,14,18$, and 19 must be reversed. The higher the score, the higher the empathy, with a range of 20-140. The validity and reliability of the English version of the scale was confirmed in Ward et al.'s study [37]. The reliability of the Scale was determined by Cronbach's alpha coefficient in a sample of nursing students $(\alpha=0.77)$ in that study [37]. In an initial study regarding the psychometric properties of the Persian version of the scale in Iran, both the internal consistency and stability of the scale, based on Cronbach's alpha coefficient $(\alpha=0.90)$ and Intra-Class Correlation (ICC) coefficient (ICC $=0.90$ ) were satisfactory within a sample of oncology nurses $(n=30)$ [40]. In the current study, Cronbach's alpha coefficient of the scale was 0.86 .

\section{Interpersonal Reactivity Index (IRI)}

In this study the Persian version of the Interpersonal Reactivity Index (IRI) with 28 items was used as a general tool for measuring empathy [40]. This tool was designed by Davis in 1980 [41]. He designed this selfreport index, considering empathy as set of constructs rather than uni-dimensional. Therefore, the IRI measures empathy in four subscales with seven items in each, including "Perspective-Taking", "Fantasy", "Empathic Concern", and "Personal Distress" [42]. The PerspectiveTaking (PT) subscale measures the tendency to take the psychological point of view of others. The Fantasy subscale (FS) measures the tendency to engage in fictional stories and imagine oneself in the situations of a fictional character. The Empathic Concern (EC) subscale measures warmth, compassion and concern for others. Finally, the Personal Distress (PD) subscale measures feelings (anxiety, discomfort), when being subjected to negative experiences of others [42]. In this tool, two subscales PerspectiveTaking and Fantasy, measure cognitive empathy and two other subscales, Empathic Concern and Personal Distress, measure emotional empathy. The respondents should select an option on a five-point Likert-type scale (score from 0 to 4 ) that best reflects their thoughts and feelings. Item numbers 3, 15 of Perspective-Taking, numbers 7, 12 of Fantasy, numbers 4, 14, 18 of Empathic Concern, and 3, 19 of Personal Distress are scored reverse. Scores in each of the subscales are separately reported. The minimum and maximum scores in each of the subscales vary between 0 and 28. The greater the score, the higher the empathy in each subscale [42]. The validity and reliability of the IRI have been confirmed in different studies in Iran and other countries [43-45]. In the current study, Cronbach's alpha coefficients for Perspective-Taking, Fantasy, Empathic Concern, and Personal Distress were $0.89,0.94,0.90$, and 0.92 , respectively.

\section{Demographic Information Questionnaire}

To assess demographic information, a Demographic Information Questionnaire with 13 questions was used. There were questions regarding age, gender, marital status, having children, educational level, having chronic diseases. Also, environmental related variables such as work experience in nursing and in the oncology field, type of employment, type of hospital ward, shift work status, job title, and sufficient monthly income were asked for.

\section{Data collection}

Data collection in this study lasted from the 1st of July until the end of September 2015. At first, the names of hospitals affiliated with three Universities of Medical Sciences in Tehran with oncology, hematology, and stem cell transplantation wards were listed. Afterwards, seven educational hospitals, that could be described as centers for cancer were selected. Subsequent to obtaining permission from the Ethical Board of Research at the Shahid Beheshti University of Medical Sciences (ethical 
code number: SBMUZ.REC.1394.55) and written permission from the universities and hospitals, the first author visited the oncology wards in the hospitals. Due to the low number of nurses in these wards, all eligible nurses based on the inclusion criteria were invited to participate in the study. The names of the eligible nurses were obtained from the nursing office in the hospital. In this way, a convenience sample of 205 nurses was entered into the study. All nurses were given verbal and written information about the study, including aims, methods and procedures of the study. In addition, they were told that participation is voluntary and that they could withdraw at any time without consequences. Each participant received a code number that was entered into the data file. During the study, confidentiality and the precision of the reported information were considered carefully. All nurses filled out a written informed consent form. A package of questionnaires with a note in the first part (explained the purposes of the study and asked the participants to respond to all the questions) and a reminder at the end (please check all the questions and don't leave them without answering), inside a closed envelope were distributed among the nurses during morning and afternoon shifts resting time by the first author. The secretary of the ward collected them 3 to 5 days later, and the first author picked them up from the nursing station. Due to attrition risk, research tools were distributed among 205 nurses. Of this number, only 181 nurses returned the tools (response rate $>88 \%$ ). The missing data was less than $2 \%$.

\section{Data analysis}

Data analysis was performed using SPSS version 21. The normal distribution of the outcome variables was analyzed by the Kolmogorov-Smirnov test. The results showed that two outcome variables, the scores of the JSE-NS version R and four subscales of the IRI, were approximately normally distributed. Therefore, parametric analyses were chosen. Independent t-test and ANOVA were used to determine the difference of empathy in nurses within demographic variables, and then significant variables were selected for the next step, multiple linear regression (MLR) analysis. The relationship between empathy and significant demographic variables were evaluated by the MLR analyses. The scores of the JSE-NS version $R$ and four subscales of the IRI were entered into the MLR tests as dependent variables.

\section{Results}

The mean age of oncology nurses was $34.9 \pm 6.7$ years, with a range of 23-54 years. Other demographic characteristics according to the scores of the JSE-NS version $\mathrm{R}$ and four subscales of the IRI have been shown in Tables 1 and 2, respectively.
Table 3 shows that the mean score of empathy in oncology nurses was $106 \pm 16.5$, using the JSE-NS version R. Also, the mean scores of empathy within four subscales of the IRI were $20.5 \pm 5.8$ (subscale of the Empathic Concern), $14.6 \pm 3.5$ (subscale of the PerspectiveTaking), $14.0 \pm 4.5$ (subscale of the Personal Distress), and $11 \pm 5.5$ (subscale of the Fantasy), respectively.

Distribution of response scores on the JSE-NS version $\mathrm{R}$ and four subscales of the IRI are also shown in Tables 4 and 5 . The results in Table 4 show that $50.3 \%$ and $43.6 \%$ of the nurses reported their empathy between 50-75, and 75-100 scores respectively. In other words, approximately $94 \%$ of oncology nurses reported their empathy between $50-100$ scores by the JSE-NS version R. However, $6.1 \%$ of the nurses reported low empathy between 25-50 scores.

Table 5 shows that the majority of nurses (57.4\%) reported their empathy between 50 and 75 scores on Perspective-Taking. But, 39.8\% of the nurses scored less than 50. The results for Empathic Concern show that $40.9 \%$ and $48.1 \%$ of the nurses reported their empathy between 50-75 and 75-100 scores, respectively. In other words, about $89 \%$ of oncology nurses reported their Empathic Concern between 50-100 scores by the IRI.

The MLR analysis result of nurses' empathy scores on the JSE-NS version $\mathrm{R}$ showed that there was a contradictory result of variables of age and work experience (there was an interaction effect between them). A Pearson correlation test showed that there is a high correlation between them $(r=0.90)$. Therefore, at first these variables entered to a linear regression analysis, one by one (a linear regression model with a single explanatory variable). The results showed that only age was significant $(\beta=0.33, p \leq 0.000)$, but not work experience. Thus, in the final MLR analysis, all significant demographic variables from the primary analyses by ANOVA and t-test were entered, except for work experience. The final MLR analysis showed that there were significant results for age $(\beta=0.22, p \leq 0.005)$, marital status $(\beta=0.21, p \leq 0.006)$, and having children $(\beta=0.19, p \leq 0.012)$, respectively. These variables totally predicted $22 \%$ of changes in scores of empathy in oncology nurses (Table 6).

The results of four MLR analyses for nurses' empathy scores on the IRI subscales showed that there were significant results for the subscale of Perspective-Taking with marital status ( $\beta=0.16, p<0.05$ ), as well as the job title $(\beta=0.18, p<0.05)$. The subscale of Personal Distress was only significant in terms of marital status $(\beta=0.20, p<0.01)$. There was a negative relationship between the subscale of Fantasy with work experience in the oncology field $(\beta=-0.27, p<0.01)$, and the risk of having chronic diseases $(\beta=-0.28, p<0.01)$. Also, there were significant relationships between the subscale of 
Table 1 Demographic group differences in the Jefferson Scale of Empathy-NS version R in oncology nurses, Tehran, Iran ( $n=181)$

\begin{tabular}{|c|c|c|c|c|}
\hline Variables & Groups & Number(\%) & Mean \pm SD & $p$ \\
\hline \multirow[t]{3}{*}{$\overline{\text { Age }(\text { year })^{d}}$} & $20-30$ & $48(26.5)$ & $99.9 \pm 13.5$ & 0.004 \\
\hline & $31-41$ & $99(54.6)$ & $106.9 \pm 18.6$ & \\
\hline & $\geq 42$ & $34(18.7)$ & $111.7 \pm 10.9$ & \\
\hline \multirow[t]{2}{*}{ Sex } & Male & 21 (11.6) & $105.6 \pm 17.2$ & 0.020 \\
\hline & Female & $160(88.3)$ & $108.6 \pm 10.7$ & \\
\hline \multirow[t]{2}{*}{ Marital Status ${ }^{\mathrm{a}, \mathrm{e}}$} & Married & $141(77.9)$ & $109.2 \pm 14.4$ & 0.001 \\
\hline & Single & $40(22.0)$ & $94.7 \pm 18.7$ & \\
\hline \multirow[t]{2}{*}{ Having children ${ }^{e}$} & Yes & $113(62.3)$ & $112.3 \pm 17.2$ & 0.001 \\
\hline & No & $68(37.6)$ & $102.0 \pm 15.4$ & \\
\hline \multirow[t]{2}{*}{ Educational Level $^{\mathrm{e}}$} & $\mathrm{BSC}^{\mathrm{b}}$ & $173(95.5)$ & $105.7 \pm 16.8$ & 0.009 \\
\hline & $M S c^{c}$ & $8(4.4)$ & $112.7 \pm 5.4$ & \\
\hline \multirow[t]{3}{*}{ Work experience in nursing (year) ${ }^{d}$} & $<1$ & $8(4.4)$ & $109.5 \pm 14.8$ & 0.010 \\
\hline & $1-4$ & $43(23.7)$ & $99.3 \pm 12.9$ & \\
\hline & $\geq 5$ & $130(71.8)$ & $108.0 \pm 17.2$ & \\
\hline \multirow[t]{3}{*}{ Work experience in oncology field (year) ${ }^{d}$} & $<1$ & $40(22)$ & $106.1 \pm 15.8$ & 0.475 \\
\hline & $1-4$ & $83(45.9)$ & $104.5 \pm 17.1$ & \\
\hline & $\geq 5$ & $58(32.0)$ & $108.0 \pm 16.2$ & \\
\hline \multirow[t]{2}{*}{ Shift work status ${ }^{e}$} & Fixed shift & 97 (53.6) & $109.4 \pm 14.9$ & 0.003 \\
\hline & Rotating shift & $84(46.4)$ & $102.1 \pm 17.5$ & \\
\hline \multirow[t]{2}{*}{ Job title } & Nurse & $162(89.5)$ & $105.8 \pm 16.8$ & 0.636 \\
\hline & Head nurse & $19(10.4)$ & $107.7 \pm 14.2$ & \\
\hline \multirow[t]{2}{*}{ Type of employment ${ }^{\mathrm{e}}$} & Official & $110(60.7)$ & $107.6 \pm 17.8$ & 0.111 \\
\hline & Contractual & $71(39.1)$ & $103.5 \pm 14.1$ & \\
\hline \multirow[t]{3}{*}{ Type of hospital ward ${ }^{d}$} & Oncology & $119(65.7)$ & $105.1 \pm 16$ & 0.159 \\
\hline & Hematology & $40(22.0)$ & $110.3 \pm 18$ & \\
\hline & Stem cell transplantation & $22(12.1)$ & $103.2 \pm 16.1$ & \\
\hline \multirow[t]{2}{*}{ Sufficient monthly income $e^{e}$} & Yes & $11(6.1)$ & $100.2 \pm 14.6$ & 0.236 \\
\hline & No & $170(93.9)$ & $106.4 \pm 16.6$ & \\
\hline \multirow[t]{2}{*}{ Chronic disease $^{e}$} & Yes & 25 (13.8) & $108.2 \pm 17.1$ & 0.482 \\
\hline & No & $156(86.2)$ & $105.6 \pm 16.5$ & \\
\hline
\end{tabular}

${ }^{a}$ Marital status is only divided into two groups, so there was no data for widowed and divorced nurses in the study

${ }^{b}$ Bachelor of Science (BSc) in Nursing

${ }^{\mathrm{C}}$ Master of Science (MSc) in Nursing

${ }^{\mathrm{d}} \mathrm{F}$ test

${ }^{e}$ t-test

Empathic Concern and variables of age $(\beta=0.39$, $p \leq 0.000)$, having children $(\beta=0.30, p \leq 0.000)$, type of employment $(\beta=0.23, p \leq 0.039)$ and type of hospital ward (oncology ward in comparison with stem cell transplantation ward: $\beta=0.14, p \leq 0.040$ ), respectively. These variables have totally predicted $32 \%$ of changes in scores of the subscale of Empathic Concern (These findings have not been shown in the Table).

\section{Discussion}

This study was carried out with the aim of determining the level and type of empathy in a sample of oncology nurses in seven educational hospitals as well as investigating the relationship between nurses' empathy and their demographic characteristics. In general, our findings showed that the majority of oncology nurses reported their empathy at the average level or above. Determination of their type of empathy showed that Empathic Concern was dominant.

Measurement of empathy with the JSE-NS version $R$ showed that the mean score of oncology nurses was $106 \pm 16.5$ (score range of 20-140). This is consistent with a study on midwifery students at one of the Australian universities, which reported $107.3 \pm 13.7$ [46]. In a study 
Table 2 Demographic group differences in the subscales of the Interpersonal Reactivity Index (IRI) in oncology nurses, Tehran, $\operatorname{Iran}(N=181)$

\begin{tabular}{|c|c|c|c|c|}
\hline Subscale & Variables & Groups & Mean \pm SD & $P$ \\
\hline \multirow[t]{9}{*}{ Perspective Taking } & \multirow[t]{2}{*}{ Marital Status ${ }^{b}$} & Married & $18.0 \pm 3.8$ & \multirow[t]{2}{*}{0.007} \\
\hline & & Single & $16.1 \pm 4.9$ & \\
\hline & \multirow[t]{3}{*}{ Work experience in oncology field (year) } & $<1$ & $19.5 \pm 3.1$ & \multirow[t]{3}{*}{0.001} \\
\hline & & $1-4$ & $16.4 \pm 4.1$ & \\
\hline & & $\geq 5$ & $18.0 \pm 4.2$ & \\
\hline & \multirow[t]{2}{*}{ Shift work status ${ }^{\mathrm{b}}$} & Fixed shift & $18.2 \pm 3.6$ & \multirow[t]{2}{*}{0.036} \\
\hline & & Rotating shift & $16.9 \pm 4.5$ & \\
\hline & \multirow[t]{2}{*}{ Job title ${ }^{b}$} & Nurse & $17.3 \pm 4.1$ & \multirow[t]{2}{*}{0.001} \\
\hline & & Head nurse & $20.3 \pm 2.9$ & \\
\hline \multirow[t]{5}{*}{ Fantasy } & \multirow[t]{3}{*}{ Work experience in oncology field (year) } & $<1$ & $14.0 \pm 5.0$ & \multirow[t]{3}{*}{0.001} \\
\hline & & $1-4$ & $10.5 \pm 6.0$ & \\
\hline & & $\geq 5$ & $9.6 \pm 4.4$ & \\
\hline & \multirow[t]{2}{*}{ Chronic disease $^{\mathrm{b}}$} & Yes & $15.0 \pm 4.7$ & \multirow[t]{2}{*}{0.001} \\
\hline & & No & $10.3 \pm 5.4$ & \\
\hline \multirow[t]{17}{*}{ Empathic concern } & \multirow[t]{3}{*}{ Age (year) $)^{a}$} & $20-30$ & $17.5 \pm 6.8$ & \multirow[t]{3}{*}{0.001} \\
\hline & & $31-41$ & $21.6 \pm 5.3$ & \\
\hline & & $\geq 42$ & $21.4 \pm 3.7$ & \\
\hline & \multirow[t]{2}{*}{$\operatorname{Sex}^{\mathrm{b}}$} & Male & $19.0 \pm 2.6$ & \multirow[t]{2}{*}{0.031} \\
\hline & & Female & $20.7 \pm 6.0$ & \\
\hline & \multirow[t]{2}{*}{ Marital Status $^{b}$} & Married & $21.4 \pm 5.5$ & \multirow[t]{2}{*}{0.001} \\
\hline & & Single & $17.1 \pm 5.6$ & \\
\hline & \multirow[t]{3}{*}{ Work experience in nursing (year) ${ }^{a}$} & $<1$ & $20.6 \pm 6.0$ & \multirow[t]{3}{*}{0.001} \\
\hline & & $1-4$ & $17.3 \pm 7.1$ & \\
\hline & & $\geq 5$ & $21.5 \pm 4.9$ & \\
\hline & \multirow[t]{2}{*}{ Shift work status ${ }^{b}$} & Fixed shift & $22.0 \pm 4.5$ & \multirow[t]{2}{*}{0.001} \\
\hline & & Rotating shift & $18.7 \pm 6.5$ & \\
\hline & \multirow[t]{3}{*}{ Type of hospital ward ${ }^{a}$} & Oncology & $20.4 \pm 5.5$ & \multirow[t]{3}{*}{0.037} \\
\hline & & Hematology & $22.1 \pm 6.0$ & \\
\hline & & Stem cell transplantation & $18.1 \pm 6.0$ & \\
\hline & \multirow[t]{2}{*}{ Having children ${ }^{\mathrm{b}}$} & Yes & $23.0 \pm 5.0$ & 0.001 \\
\hline & & No & $19.0 \pm 5.7$ & \\
\hline Personal Distress & Marital Status ${ }^{\mathrm{b}}$ & Married & $14.6 \pm 4.3$ & 0.001 \\
\hline & & Single & $11.9 \pm 4.7$ & \\
\hline & Having children ${ }^{\mathrm{b}}$ & Yes & $14.9 \pm 3.5$ & 0.034 \\
\hline & & No & $13.5 \pm 5.0$ & \\
\hline & Chronic disease $^{b}$ & Yes & $16.1 \pm 3.8$ & 0.013 \\
\hline & & No & $13.7 \pm 4.5$ & \\
\hline
\end{tabular}

\section{${ }^{\mathrm{a}} \mathrm{F}$ test}

bt-test

by Ward and colleagues [37], the mean score of empathy for American nursing students in different educational levels was reported $114 \pm 11.5$. This difference can be related to a different context, various study groups or other methodological differences.
In spite of the three-factor structure of empathy (perspective-taking, compassionate care, and walking in the patient's shoes) in the original version of the JSE [35], in the Persian version of the JSE-NS version R, a four-factor structure was confirmed by a sample of oncology nurses [40]. 
Table 3 Mean, standard deviation (SD) and Median for the Jefferson Scale of Empathy-NS version R (JSE-NS version R) and subscales of the Interpersonal Reactivity Index in oncology nurses, Tehran, Iran ( $N=181)$

\begin{tabular}{|c|c|c|c|c|c|c|c|}
\hline Variables & Mean \pm SD (Raw scores) & Mean \pm SD $(0-100)^{a}$ & Scale range & Measured range & 25th percentile & Median & 75th percentile \\
\hline JSE-NS version $R$ & $106 \pm 16.5$ & $71.67 \pm 13.75$ & $20-140$ & $55-131$ & 97 & 108 & 117 \\
\hline Perspective Taking & $14.6 \pm 5.3$ & $52.14 \pm 18.93$ & $0-28$ & $5-22$ & 12 & 15 & 17 \\
\hline Fantasy & $11 \pm 5.5$ & $39.28 \pm 19.64$ & $0-28$ & $0-23$ & 8 & 9 & 15.5 \\
\hline Empathic Concern & $20.5 \pm 5.8$ & $73.21 \pm 20.71$ & $0-28$ & $5-28$ & 18 & 20 & 25 \\
\hline Personal Distress & $14 \pm 4.5$ & $50.00 \pm 16.07$ & $0-28$ & $4-23$ & 10.5 & 15 & 16 \\
\hline
\end{tabular}

${ }^{\text {a }}$ The scores of the JSE-NS version R linearly transformed into a 100-point Scale

Therefore, in the present study the score of the JSE-NS version $\mathrm{R}$ was used in total, and its subscales were not reported separately. Hence, it might be not able to clearly judge the type of nurses' empathy by the JSE-NS version R. However, specialists presume that the JSE covers only one important aspect of empathy, attitudes towards empathic behavior $[47,48]$. With this interpretation, it seems that the majority of oncology nurses in our study reported positive attitudes towards empathic behavior in confronting cancer patients, which can be justified based on the particular situation of cancer patients, the nature of disease and the close communication of nurses with them [7]. Nevertheless, around $6 \%$ of the nurses reported low empathy, which suggests future qualitative research to explore the special reasons and characteristics of this group. Studies show that individual characteristics of persons can influence their empathy $[49,50]$.

A review to the subscales of the IRI shows that empathy mean score of the nurses in Empathic Concern were higher than for the other subscales $(20.5 \pm 5.8)$ (score range of $0-28$ ). The results of our study were consistent with the findings of a similar study in Polish nurses, which reported higher mean score in Empathic Concern $(19.2 \pm 4.1)$, than in the other subscales [51]. On the other hand, according to our results about $89 \%$ of oncology nurses reported average score or higher for Empathic Concern. Thus, it seems that in our study the emotional component of empathy is stronger than the cognitive component in oncology nurses. Even though the mean score of empathy of nurses in the subscale of Perspective-Taking was not low $(14.6 \pm 3.8)$ (score range

Table 4 Distribution of response scores on the Jefferson Scale of Empathy-NS version R (JSE-NS version R) ${ }^{\mathrm{a}}$ in oncology nurses, Tehran, Iran $(N=181)$

\begin{tabular}{|c|c|c|}
\hline JSE-NS version $\mathrm{R}$ scores $^{\mathrm{a}}$ & $\begin{array}{l}\text { Frequency } \\
(\%)\end{array}$ & $\begin{array}{l}\text { Cumulative frequency } \\
\text { (\%) }\end{array}$ \\
\hline $25-50^{b}$ & $11(6.1)$ & $11(6.1)$ \\
\hline $50-75$ & $91(50.3)$ & $102(56.4)$ \\
\hline 75-100 & 79 (43.6) & $181(100)$ \\
\hline Sum & $181(100)$ & -—- \\
\hline
\end{tabular}

aThe scores of the JSE-NS version $\mathrm{R}$ linearly transformed into a 100-point scale ${ }^{\mathrm{b}}$ There was no data for floor less than 25 score of $0-28$ ), about $39 \%$ of the nurses scored below the subscale mean. Evidence shows that barriers for nurses' empathy can be associated with a personality style [52] or may be found in a clinical environment [53]. These are, for example, lack of time, lack of support from colleagues, anxiety about patients [52], exposure to negative health workers [53], expanding caring roles, and workload [54]. However, advocates of Peplau's Interpersonal Theory claimed time limitation is not an obstacle in establishing interpersonal relationships with patients [55].

The results of regression models based on the JSE-NS version $R$ showed that the variables of age, marital status, and having children have respectively influence on nurses' empathy. They all together predicted $22 \%$ of changes in the empathy scores of the nurses. Arguably, the reason for increasing level of empathy with increasing age may be related to growing life experience [56]. It was contrary to Trevizan and colleagues' study [57], who did not find any effect of age on the level of Brazilian nurses' empathy. In parallel to our finding, the results of a cross-sectional study in different health professions in two Australian universities showed that $26-30$ years old and $31-35$ years old students had higher empathy scores by the JSE than their younger classmates [32]. Furthermore, in our study the nurses who were married or had children reported higher empathy, but these effects were not found in Turkish oncology nurses [58]. Although, our findings didn't show any correlation between nurses' level of empathy and their work experience in the nursing field, earlier studies showed different results, from no changes in empathy [58, $59]$ to empathy reduction $[57,60]$ or increase [50].

Similarly, the results of multiple linear regression models with the IRI subscales showed comparable results. Marital status had a significant correlation with two subscales scores, Perspective Taking and Personal Distress. This means that married nurses achieved a higher score of empathy in the subscale of PerspectiveTaking (cognitive component of empathy) than single ones. They tried to put themselves in the place of the patients, felt higher anxiety and discomfort from negative experiences of the patients. In addition, a set of variables, including age, having children, type of employment and type of hospital ward explained respectively $32 \%$ of the 
Table 5 Distribution of response scores on the subscales of the Interpersonal Reactivity Index (IRI), in oncology nurses, Tehran, Iran $(N=181)$

\begin{tabular}{|c|c|c|c|c|c|c|c|c|}
\hline \multirow[t]{2}{*}{ IRI subscale ${ }^{a}$} & \multicolumn{2}{|c|}{ Perspective taking } & \multicolumn{2}{|l|}{ Fantasy } & \multicolumn{2}{|c|}{ Empathic concern } & \multicolumn{2}{|c|}{ Personal distress } \\
\hline & $\begin{array}{l}\text { Frequency } \\
(\%)\end{array}$ & $\begin{array}{l}\text { Cumulative } \\
\text { frequency } \\
(\%)\end{array}$ & $\begin{array}{l}\text { Frequency } \\
\text { (\%) }\end{array}$ & $\begin{array}{l}\text { Cumulative } \\
\text { frequency } \\
(\%)\end{array}$ & $\begin{array}{l}\text { Frequency } \\
(\%)\end{array}$ & $\begin{array}{l}\text { Cumulative } \\
\text { frequency } \\
(\%)\end{array}$ & $\begin{array}{l}\text { Frequency } \\
(\%)\end{array}$ & $\begin{array}{l}\text { Cumulative } \\
\text { frequency } \\
\text { (\%) }\end{array}$ \\
\hline$<25$ & $5(2.8)$ & $5(2.8)$ & $39(21.5)$ & $39(21.5)$ & $12(6.6)$ & $12(6.6)$ & $15(8.3)$ & $15(8.3)$ \\
\hline $25-50$ & $67(37.0)$ & $72(39.8)$ & $90(49.7)$ & $129(71.2)$ & $8(4.4)$ & $20(11.0)$ & $64(35.4)$ & $79(43.7)$ \\
\hline $50-75$ & $104(57.4)$ & $176(97.3)$ & $51(28.2)$ & $180(99.4)$ & $74(40.9)$ & $94(51.9)$ & $90(49.7)$ & $169(93.4)$ \\
\hline $75-100$ & $5(2.8)$ & $181(100)$ & $1(0.6)$ & $181(100)$ & $87(48.1)$ & $181(100)$ & $12(6.6)$ & $181(100)$ \\
\hline Sum & $181(100)$ & -———- & $181(100)$ & -———- & $181(100)$ & -——- - & $181(100)$ & -二-- \\
\hline
\end{tabular}

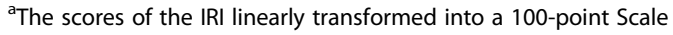

changes in Empathic Concern of the oncology nurses. Previous studies in the field of Empathic Concern showed that younger people reported less emotional empathy when watching video, compared to older people [61]. Moreover, in a study which was carried out in the US Brandeis University, the mean score of Empathic Concern in healthy young and older adults was reported $20.9 \pm 4.9$ and $21.3 \pm 3.3$, respectively [62]. The official nurses reported higher empathy than the contractual ones, consistent with a previous study on Iranian oncology nurses [50]. It seems that official nurses due to his/her job conditions experience more career development opportunities and individual achievement [50]. Also, our results showed that the nurses who worked in oncology wards reported higher empathy compared to those who worked in stem cell transplantation wards. One of the main reasons of this difference can be related to the high number of nurses in oncology wards in our study. However, it is not easy to compare nurses' empathy based on wards type and their patients. The results of previous studies showed nurses' empathic behaviors in cancer wards for cancer patients [7, 63]. A recent qualitative study in caring experience of
Iranian nurses showed that they developed empathic behaviors and compassion toward hematopoietic stem cell transplantation patients [64]. In Buyuk et al.'s study [58], there was no difference between oncology nurses' empathy in adults and pediatric wards.

In Summary, results of this study showed that empathy in this sample of oncology nurses is more emotional than cognitive. As a cognitive response opposite to an emotional one is more dependent on subjective judgments [11], there is a possibility to increase the level of empathy significantly in nurses by focusing on it; teaching during 3-6 months and measuring it [26]. In-service training programs of empathic communication skills [65] with a focus on oncology nurses' experiences, supervised clinical work, regular meetings with a supervisor, periodic measurements of empathy and giving a positive feedback to the nurses can be useful ways. Further research is recommended to investigate the environmental factors influencing oncology nurses' empathy.

\section{Strengths and Limitations}

A combination of both general and specialized tools was used in this study to collect more information about

Table 6 The results of Multiple Linear Regression analysis for the Jefferson Scale of Empathy-NS version R (JSE-NS version R) scores in oncology nurses, Tehran, Iran ( $N=181)$

\begin{tabular}{|c|c|c|c|c|c|}
\hline Independent variable & Unstandardized B & SE & Standardized $\beta$ & $\mathrm{t}$ & $p$ \\
\hline Constant & 68.5 & 14.0 & - & 4.9 & 0.000 \\
\hline Age & 0.54 & 0.2 & 0.22 & 2.8 & 0.005 \\
\hline Marital statusa & 8.6 & 3.1 & 0.21 & 2.8 & 0.006 \\
\hline Having children & 6.5 & 2.5 & 0.19 & 2.5 & 0.012 \\
\hline Gender & -4.5 & 3.8 & -0.09 & -1.2 & 0.237 \\
\hline Shift work status & -0.3 & 0.9 & -0.03 & -0.4 & 0.704 \\
\hline Educational level & 3.8 & 6.0 & 0.05 & 0.6 & 0.531 \\
\hline
\end{tabular}

$R^{2}=0.22$

Dependent variable: JSE-NS version R scores; Significant variables are shown bold

The independent variables were classified as 1, 2 in the two group variables and 1, 2, 3 in the three group variables. The number-one was considered as Reference Group

${ }^{a}$ Marital Status, including married \& single 
empathy in the field of oncology nursing. Since, there has been no tool for measuring of empathy in oncology nurses, we used a nursing student version of the JSE that has previously been validated and showed reliability in a sample of Iranian oncology nurses [40]. Using selfreported tools are the easiest way to collect data, but it brings some disadvantages, such as recall bias and response-choice order effect [66]. The generalization of the results should be cautious due to individuals' inherent empathy and convenience sampling in this study.

\section{Conclusions}

The results of this study in general showed that the majority of oncology nurses have positive attitudes towards empathic behavior with cancer patients and reported their level of empathy as average or higher. But Empathic Concern as one of the emotional components of empathy was stronger than the cognitive component in Iranian oncology nurses. Thus, empathy in this sample of nurses is more emotional than cognitive. So, there is a special place to focus on the cognitive component of empathy. The cognitive filter of empathy allows empowering oncology nurses in this field. In-service training programs with a focus on nurses' experiences, supervised clinical works, and periodic measurements can be effective, improving genuine clinical empathy with patients and thereby caring.

\section{Abbreviations}

EC: Empathic concern; FS: Fantasy scale; IRI: Interpersonal reactivity index; JSE-NS version R: Jefferson scale of empathy-nursing student version $\mathrm{R}$; MLR: Multiple linear regression; PD: Personal distress; PT: Perspective-taking

\section{Acknowledgements}

We hereby thank all of the nurses in the oncology, hematology and stem cell transplantation wards of educational hospitals affiliated to Tehran Universities of Medical Sciences who helped in completing the questionnaires.

\section{Availability of data and materials}

The Persian translation of the JSE-NS version $\mathrm{R}$ which was translated and tested in a previous study by the authors, are freely available to any scientist willing to use it.

\section{Funding}

The authors declare that they have no funding for this study.

\section{Authors' contributions}

Data was collected and computerized by MSK. MSK and MN analyzed the data together. MSK and CR interpreted the data. All of the authors contributed in drafting of the manuscript and critical revisions. CR did the planning and design of the study, study supervision and revisions of the English language of the article. All authors read and approved the final manuscript.

\section{Ethics approval and consent to participate}

This study was registered with SBMUZ.REC.1394.55 ethical code from Shahid Beheshti University of Medical Sciences. Participants were asked to respond anonymously to all the questions, if they wanted to participate in the study. Oral and written informed consent was obtained from all the nurses, and they were assured that participation in this study is voluntary, all information is confidential and that they could withdraw whenever they want.

\section{Consent for publication}

Written informed consent and consent for publication was provided by the participants of the study.

\section{Competing interests}

The authors declare that they have no competing of interest.

\section{Publisher's Note}

Springer Nature remains neutral with regard to jurisdictional claims in published maps and institutional affiliations.

\section{Author details}

${ }^{1}$ Department of Nursing, School of Nursing \& Midwifery of Shahid Beheshti University of Medical Sciences, Tehran, Iran. ${ }^{2}$ Department of Nursing, School of Medical Sciences, Tonekabon Branch, Islamic Azad University, Tonekabon, Iran.

Received: 9 December 2016 Accepted: 20 June 2017

Published online: 03 July 2017

\section{References}

1. Micheli A, Coebergh JW, Mugno E, et al. European health systems and cancer care. Ann Oncol. 2003;14(suppl 5):v41-60.

2. Goya M. Iranian Annual Cancer Registration Report.Ministry of Health and MedicalEducation, Health Deputy, Center for Disease Control and Prevention; 2005.

3. Asadi-Lari M, Goushegir S, Majd Z, Latifi NA. Spiritual care at the end of life in Islamic context, asystemic review. Iran J Cancer Prev. 2008;1(2):63-7.

4. Kennifer S, Alexander S, Pollak K, et al. Negative emotions in cancer care: do oncologists'responses depend on severity and type of emotion. Patient Educ Couns. 2009;76(1):51-6. doi:10.1016/j.pec.2008.10.003.

5. Alligood MR. Rethinking empathy in nursing education: shifting to a developmental view. Annu Rev Nurs Educ. 2005:3:299-309.

6. Chinn P, Kramer M. Integrated Theory and Knowledge Development in Nursing. 7th ed. Philadelphia: Mosby; 2007.

7. Watts R, Botti M, Hunter M. Nurses' perspectives on the care provided to cancer patients. Cancer Nurs. 2010;33(2):E1-8. doi:10.1097/NCC. Ob013e3181b5575a.

8. Legg MJ. What is psychosocial care and how can nurses better provide it to adult oncology patients. Aust J Adv Nurs. 2011;28(3):61-7.

9. Muriel A, Hwang V, Kornblith A, et al. Management of psychosocial distress by oncologists. Psychiatr Serv. 2009;60(8):1132-4.

10. Chowdhry S. Exploring the concept of empathy in nursing: can it lead to abuse of patient trust? Nurs Times. 2010;106(42):22-5.

11. Hojat M. Empathy in patient care: Antecedents,development, measurement, and outcomes. Philadelphia: Springer Science \& Business Media; 2007.

12. Batson CD, Shaw LL. Evidence for altruism: Toward a pluralism of prosocial motives. Psychol Inq. 1991;2(2):107-22.

13. Van der Singel M. Compassion in care: A qualitative study of older people with a chronic disease and nurse. Nurs Ethics. 2011;18(5):672-85.

14. Dal santo DL, Pohl S, Saiani L, Battistelli A. Empathy in the emotional interactions with patients. Is it positive for nurses too? J Nurs Educ Pract. 2014:4(2):74-81.

15. Vreeke GJ, van der Mark IL. Empathy, an integrative model.New Ideas. Psycho. 2003;21(3):177-207.

16. Yu J, Kirk M. Measurement of empathy in nursing research: Systematic review. J Adv Nurs. 2008;64(5):440-54.

17. Kirk T. Beyond empathy: clinical intimacy in nursing practice. Nurs Philos. 2007;8(4):233-43.

18. Clark AJ. Empathy: An integral model in the counseling process. J Couns Dev. 2010;88:348-56

19. Rieffe C, Ketelear L, Wiefferink CH. Assessing empathy in young children: construction and validation of an empathy questionnaire (EmQue). Pers Indiv Differ. 2010;49:362-7. doi:10.1016/j.paid.2010.03.046.

20. De Sousa A, Mcdonald S, Rushby J, Li S, Dimoska A, James C. Understanding deficits in empathy after traumatic brain injury: The role of affective responsivity. Cortex. 2011;47(5):526-35.

21. Tully ER, Amess AM, Garcia SE, Donohue MR. Quadratic associations between empathy and depression as moderated by emotion dysregulation. Aust J Psychol. 2015;00(0):1-25

22. Davis MH. Empathy: A social psychological approach. Boulder: Westview Press; 1996

23. Larson $E$, Yao X. clinical empathy as emotional labor in the patient- physician relationship. J Am Med Assoc. 2005:293(9):1100-6.

24. Stepien K, Baernstein A. Educating for empathy. J Gen Int Med. 2007;21:524-30 
25. Reynolds W, Scott PA, Austin W. Nursing, empathy and perception of the moral. J Adv Nurs. 2000;32(1):235-42.

26. Mercer S, Reynolds W. Empathy and quality of care. Brit J Genl Pract. 2002;52:S9-S13.

27. Coulehan JL, Platt FW, Egener B, Frankel R, Lin CT, Lown B, et al. "Let me see if $\mathrm{i}$ have this right...": words that help build empathy. Ann Intern Med. 2001;135(3):221-7.

28. Association of American Medical Colleges. (2008). Recommendations for Clinical Skills Curricula for Undergraduate Medical Education. Retrieved from https://www.aamc.org/download/130608/data/clinicalskills_oct09.qxd.pdf. Accessed 25 July 2017

29. Davis MH, Luce C, Kraus JD. The heritability of characteristics associated with disposititional empathy. J Pers. 1994;62(3):369-91.

30. Reb A. Transforming the death sentence: Elements of hope in women with advanced ovarian cancer. Oncol Nurs Forum. 2007;34(6):70-81.

31. Beck R, Daughtridge R, Sloane P. Physician- patient communication in the primary care office: A systematic review. J Am Board Fam Pract. 2002;15(1):25-38.

32. Williams B, Brown T, McKenna L, Boyle M, Palermo C, Nestel D, et al. Empathy levels among health professional students: a cross-sectional study at two universities in Australia. Adv Med educ pract. 2014;5:107-13. doi:10.2147/AMEP.S57569.

33. Amani A, Esfandyari H, Gholami M. The Role of Problem Solving Strategies in Empathy with Patients in Sanandaj Nurses. J Psychol Psychiat Shenakht. 2014;1(1):39-49.

34. Parvan K, Ebrahimi H, Zamanzadeh V, Seyedrasooly A, Dadkhah D, Jabarzadeh F. Empathy from the Nurses' Viewpoint in Teaching Hospitals of Tabriz University of Medical Sciences. Iran J Care Scis. 2014;3(1):29-36. doi: 10.5681/jcs.2014.004.

35. Hojat M, Joseph S, Gonnella JS, Mangjone S, Nasca TJ. Physician Empathy: Definition, components, measurement and Relationship to Gender and specialty. Am J Psychiat. 2002;159(9):1563-9. doi:10.1176/appi.ajp.159.9.1563.

36. Williams B, Brown T, Boyle M, Dousek S. Psychometric testing of the Jefferson Scale of Empathy Health Profession Students' version with Australian paramedic students. Nurs Health Sci. 2013;15(1):45-50. doi:10. 1111/j.1442-2018.2012.00719.

37. Ward J, Schaal M, Sullivan J, Bowen M, Erdmann J, Hojat M. Reliability and Validity of the Jefferson Scale of Empathy in Undergraduate Nursing Students. J Nurs Meas. 2009:17(1):73-88,

38. Hojat M, Mangione S, Kane GC, Gonnella JS. Relationships between scores of the Jefferson Scale of Physician Empathy (JSPE) and the Interpersonal Reactivity Index IRI. Med Teach. 2005;27(7):625-8.

39. Thomas Jefferson University. Center for Research in Medical Education \& Health Care: Jefferson Scale of Empathy. 2016. http:// www.jefferson.edu/ university/skmc/research/research-medical-education/jefferson-scaleofempathy.html. Accessed 23 July 2016.

40. Sedaghati Kesbakhi M, Rohani C, Mohtashami J, Nasiri M. Validity and Reliability of the Jefferson Scale of Empathy-Nursing Student Version R in a Sample of Iranian Oncology Nurses. Nurs Midwifery Stud. 2016. In press :e39505. Published online 2016 November 1. doi:10.17795/nmsjournal39505.

41. Davis MH. A multidimensional approach to individual differences in empathy. JSAS Catalog Select Documents in Psychology. 1980;10(85):1-19.

42. Davis MH. Measuring individual differences in empathy: evidence for a multidimensional approach. J Pers Soc Psychol. 1983;44(1):113-26.

43. Feizabadi Z, Farzad V, Shahrarai M. The relationship between empathy and identity styles and commitment in students of technical and humanities. J Psychol Stud. 2006;3(2):65-90.

44. Gilet A-L, Mella N, Studer J, Grühn D, Labouvie-Vief G. Assessing dispositional empathy in adults: A French validation of the Interpersonal Reactivity Index (IRI). Can J Behav Sci. 2013;45(1):42-8. doi:10.1037/a0030425.

45. Fernandez AM, Dufey M, Kramp U. Testing the Psychometric Properties of the Interpersonal Reactivitylndex (IRI) in Chile Empathy in a Different Cultural Context. Eur J Psychol Assessment. 2011;27(3):179-85. doi:10.1027/ 1015-5759/a000065.

46. Mckenna L, Boyle M, Brown T, Williams B, Molloy A, Lewis B, et al. Levels of empathy in undergraduate midwifery students: an Australian cross- sectional study. Women Birth. 2011;24(2):80-4. doi:10.1016/j.wombi.2011.02.003.

47. Hojat M, Gonnella J, Mangione S, Nasca TJ, Veloski J, Erdmann JB, et al. Empathy in medical student as related to academic performance, clinical competence and gender. Med Educ. 2002;36(6):522-7.

48. Preusche I, Wagner-Menghin M. Rising to the challenge: cross-cultural adaptation and psychometric evaluation of the adapted German version of the Jefferson Scale of Physician Empathy for students (JSPE-S). Adv Health Sci Educ Theory Pract. 2013;18:573-85. doi:10.1007/s10459-012-9393-9.

49. Cuff B, Brown SJ, Taylor L, Howat D. Empathy: a review of the concept. Emotion Rev. 2016:8(2):144-53.

50. Taleghani F, Ashouri E, Saburi M. Empathy, Burnout, Demographic Variables and their Relationships in Oncology Nurses. Iran J Nurs Midwifery Res. 2017;22(1):41-5.

51. Marcysiak M, Dąbrowska O, Marcysiak M. Understanding the concept of empathy in relation to nursing. Prog Health Sci. 2014;4(2):75-81.

52. Price V, Archbold J. What's it all about, empathy? Nurs Educ Today. 1997;17(2):106-10.

53. Ward J, Cody J, Schaal M, Hojat M. The empathy enigma: an empirical study of decline in empathy among undergraduate nursing students. J Prof Nurs. 2012;28(1):34-40.

54. Reid-Ponte P. Distress in cancer patients and primary nurses' empathy skills. Cancer Nurs. 1992;15(4):247-312.

55. McCamant KL. Humanistic nursing, interpersonal relations theory, and the empathy-altruism hypothesis. Nurs Sci Q. 2006;19(4):354-8.

56. Seyed Mirzaie SM. Some Observations on the Dimensions of Aging With a Look at Japan's Experience. Hum Sci. 2007;53:201-22.

57. Trevizan MA, dos Santos Almedia RG, Souza MC, Mazzo A, Costa Mendes LA Empathy in Brazilian nursing professional: A descriptive study. Nurs Ethics. 2015;22(3):367-76. doi:10.1177/0969733014534872.

58. Buyuk ET, Rizalar S, Güdek E, Güney Z. Evaluation of Empathetic Skills of Nurses Working in Oncology Units in Samsun. Turkey Int I Care Sci. 2015:8(1):131-9.

59. Azma K, Goodarzi N, Tavakolian E, Yadegarian F. The difference between Mu suppression and nurses' empathy with the difference of three years of work experience. Mater Sociomed. 2015;27(6):417-20. doi:10.5455/msm.2015.27.417-420.

60. Raiziene S, Endriulaitiene A. The relations among empathy, occupational commitment, and emotional exhaustion of nurses. Medicina(Kaunas). 2007:43(5):425-31.

61. Sze J, Gyurak A, Goodkind MS, Levenson RW. Greater emotional empathy and prosocial behavior in late life. Emotion. 2012:12:1129-40. doi:10.1037/a0025011.

62. Beadle J, Paradiso S, Kovach C, Polgreen L, Denburg N, Tranel D. Effects of Age-related Differences in Empathy on Social Economic Decision-Making. Int Psychol Geriatrics. 2012;24(5):822-83. doi:10.1017/S1041610211002547.

63. Kendall $\mathrm{S}$. Witnessing tragedy: nurses' perceptions of caring for patients with cancer. Int J Nur Pract. 2007;13(2):111-20.

64. Zamanzadeh V, Valizadeh L, Sayadi L, Taleghani F, Howard F, Jeddian A. Emotional Labour of Caring for Hematopoietic Stem Cell Transplantation Patients: Iranian Nurses' Experiences. Asian Nurs Res. 2013;7:91-7.

65. Kahriman I, Nural N, Arslan U, Topbas M, Can G, Kasim S. The Effect of Empathy Training on the Empathic Skills of Nurses. Iran Red Crescent Med J. 2016;18(6):e24847

66. Bowling A. Mode of questionnaire administration can have serious effects on data quality. J Pub Health. 2005;27(3):281-91. doi:10.1093/pubmed/ fdi031.

\section{Submit your next manuscript to BioMed Central and we will help you at every step:}

- We accept pre-submission inquiries

- Our selector tool helps you to find the most relevant journal

- We provide round the clock customer support

- Convenient online submission

- Thorough peer review

- Inclusion in PubMed and all major indexing services

- Maximum visibility for your research

Submit your manuscript at www.biomedcentral.com/submit 